\title{
The Relationship between the Literature Criticism of Wei, Jin, Southern and Northern Dynasties and the Study of Poetics in the Study of Confucian Classics
}

\author{
Yun Song, Yilin Tian \\ Aba Teachers University, Wenchuan, China \\ Email: hngyms2021@126.com
}

How to cite this paper: Song, Y. and Tian, Y.L. (2021) The Relationship between the Literature Criticism of Wei, Jin, Southern and Northern Dynasties and the Study of Poetics in the Study of Confucian Classics. Open Access Library Journal, 8: e8127. https://doi.org/10.4236/oalib.1108127

Received: October 28, 2021

Accepted: December 5, 2021

Published: December 8, 2021

Copyright $\odot 2021$ by author(s) and Open Access Library Inc.

This work is licensed under the Creative Commons Attribution International License (CC BY 4.0).

http://creativecommons.org/licenses/by/4.0/

\section{(c) (i) Open Access}

\begin{abstract}
The study of Confucian classics reflects the value system of Chinese culture. In the Wei, Jin, Southern and Northern Dynasties, there was a close relationship between the study of Confucian classics and literature, or there was no absolute boundary between them. In particular, the literature of literary criticism in the Wei, Jin, Southern and Northern Dynasties had a close relationship with Poetics in the Confucian classics. It can be seen from some literature comments that they are mostly influenced by the poetry teaching concepts in Poetics. This paper aims to expatiate on the relationship and interaction between the literary criticism in the Wei, Jin, Southern and Northern Dynasties and the study of Poetics in the study of Confucian classics.
\end{abstract}

\section{Subject Areas}

History, Literature

\section{Keywords}

The Study of Poetics, Literary Criticism, Wei, Jin, Southern and Northern Dynasties, Confucian Classics

\section{1. 前言}

经学自古至今, 绵延长久, 呈现出我国传统文化的价值内核, 被誉为传 统文化之躯体。那什么是经学呢? 按照姜广辉先生的观点阐释经学, 则涵盖 了 “十三经” 的训诂注疏、义理阐释等等, 是历史的圣贤制定的思想准则与 行为规范。具体而言即是关于 “十三经” 等经典的训诂注疏、义理阐释以及 
学派、传承、演变等等的学问, 同时也是思想准则与行为规范。“十三经” 即指汉代立《诗经》《尚书》《周易》《礼记》《春秋》于学官, 为五经; 唐代加《周礼》 《仪礼》, 并与《春秋三传》为九经; 后加《孝经》 《论语》

《尔雅》为十二经; 南宋加入 《孟子》共十三部典籍。本质而言, 经学的作 用即维持社会整体性及相对一致性, 影响社会生活方式, 使人具有高尚的道 德, 形成能够增强民族凝聚力的文化精神。经学中《诗》学即指汉代《诗经》 的学术研究。

魏晋南北朝时期的文学理论和文学作品硕果累累, 风格趋于多样化及个 性化。五古在魏晋南北朝达到创作顶峰, 诗学挣脱儒家经学的束缚, 政治教 化已不是文学创作的唯一标准。同时, 文帝立四学, 即文学有了一席之地, 与玄学、史学、儒学并列, 成为一个独立的门类。这一时期, 刘劦区分 “文 笔”, 以有韵无韵来加以判断, 同时风骨、气韵、意象、声律、比兴等也成 为普遍的创作追求。这一时代文学创作的一个重要特点是文学服务于政治教 化的要求减弱, 社会功利目的性减弱, 成为个人行为。诗歌、音乐、绘画等 各类文艺形式形成各自美学追求, 在魏晋南北朝期间特别是文学发生了巨大 的变化, 文学的自觉和文学创作的个性化, 最为突出也最具意义。

“经” 有典则法规、通用常行之意, 即可以泛称中国古代儒家、墨家、 道家、法家及其他诸家各自所称的 “经” 或者经典。自汉武帝 “独尊儒术” 之后, “经” 开始集中指代以《诗经》与《尚书》为代表的儒学经典。这种 意义上的 “经” 或经典是专称, 但是 “经” 最主要的还是指儒家的经典。经 学的历史可以追溯到周公。周代起始, 《诗》已被视为政治礼仪的基础措施。 其后孔子进行删减调整, 《诗》逐渐被奉为儒家经典。在春秋时代经学有了 发展, 通过《左传》和《国语》可以看出经学在此时进入了成长阶段。西汉 与东汉则是中国经学日益拓展的重要节点。《毛诗序》提出, 汉代文学思潮 主流趋向, 正是提倡诗歌情感一者基于自然油然生成, 同样必须接受源自于 礼法的限制与制约。其作用在家庭生活中使得夫妻、子女关系融洽, 促使教 化美满、移风易俗。即 “发乎情, 止乎礼义”, “经夫妇, 成孝敬, 厚人伦, 美教化, 移风俗” [1], 《毛诗序》依托儒家伦理, 用于引导情感, 肯定诗歌 其在引导教化范畴的价值。基于此, 汉代文学批评常常以《毛诗序》议点作 为基准, 针对文学展开深度评判。经学与文学本就错综关联, 彼此交错。这 其中的差异往往只是基于一个观念和视角的不同。周王朝认定《诗》为维持 政治礼仪的措施, 其性质与两汉奉《诗》为圭臬一样。均属于某一文籍于历 史背景之下, 因为人们的认识及需要的差异所导致的一些理解上的不同。至 于魏晋南北朝, 当时学者开始探讨经与文内在关联, 突破经文禁锢, 呈现出 热烈且频繁的互动形式。

\section{2. 经学与魏晋南北朝文学批评之关系}

汉代经学光华灿烂, 影响深远, 进一步呈现别具一格的经学范畴, 生成 了极其特色的理论话语。其中《诗》学理论于魏晋南北朝之中有着深厚影响。 陆机阐释了 “诗缘情而绮靡” 这一理念, 实质正是经学 “发乎情, 止乎礼义” 的一种转换。陆机表示诗歌必须呈现艳丽华美之外在, 此理论有效促进诗歌 
理论发展, 同时对于相关的诗歌创作亦有推动。《毛诗序》位于《礼记乐记》 之后, 其阐释了 “情动于中而形于言” 这一理念 [1]。《汉书 - 翼奉传》更是 将《诗》之学视为情性[2]。已开始涉及诗与情的问题, 但未把 “言情” 提到 与 “言志” 同等的地位。《文赋》首先提出 “缘情” 这个概念, 《晋书・陆机 传》对于陆机加以评价, 称之为 “以文章冠世, 伏膺儒术, 非礼不动” [3]。 冊庸置疑, 魏晋南北朝此阶段的文学批评肯定文学特征之余, 同时汲取儒家 经学精华。尤其是推崇《诗》学, 所谓文学是在它的基础上, 用了自己的语 言来表述罢了。

刘劦思被誉为魏晋南北朝独树一帜的文学理论家典范, 其《文心雕龙》之 影响更是举世无双。《文学雕龙》之中提及《明道》、《征圣》以及《宗经》 等篇章, 能够清晰感受到经学直接引导着文学发展, 同时更是奠定了文论导 向。《文心雕龙 情采》阐释了 “为情造文” 以及 “为文造情” 等思路。为情 而造文探讨了诗人风雅以及辞人汉赋二者在写作理念上的差异性。前者吟咏 性情, 后者沽名钓誉; 前者是倾吐胸中情思进行的串座, 采用一定的表现形 式来表达自己的真情实感, 后者则是没什么真情实感却徒饰文采。刘恊阐释 了 “为情造文” 这一理念, 显然正是汲取汉代《诗》学 “情性” 论并予以拓 展。汉代基于 “情性” 进行论诗, 此举确有着独创性。文学家于创作之时, 以情性为桨, 随心所荡, 形诸舞咏。这些例子, 一并可以说明这个问题。

综合观之, 汉代《诗》学的兴盛, 进一步为魏晋南北朝文学批评提供重 要导向。尤其是 “为情造文” 更是有着直接关联。除此之外, 文学批评领域 之中文学, 以及《诗》学等经学之间的交流, 同样在以《诗》论《骚》评赋 等层面极其凸显。曹丕有着 “诗赋欲丽” 这一论点, 其与扬雄观点 “诗人之 赋丽以则, 词人之赋丽以淫” 具备类同性[4]。刘劦思在其 《文心雕龙》中针对 屈原作品等楚辞代表加以评析时, 同样恪守汉代儒学理念。《辩骚》中开篇 即围绕汉代辞赋评论展开系统归纳与论述, 最终指出楚辞 “同于《风》、《雅》 者也” “乃《雅》、《颂》之博徒” [5]。

\section{3. 经学与魏晋南北朝文学批评领域文学之互动}

诗歌于魏晋南北朝阶段, 实则正是承袭汉儒趋势予以延伸。《文章流别 论》中谈到赋是陈述性文体, 借助物象、事例阐明礼仪教化的问题, 抒发自 己的情感。然而, 借助的物象不符合现实, 文学创作辞藻过于标准、华丽就 不能很好表达文章意旨, 背离了真实情感。受此影响, 出现司马迁割相如之 浮说, 扬雄则是由于当时创作之风过于奢华深感无奈。汉朝以《诗》为则理 念的传承与沿袭。辞赋视为《诗》, 基于诗教思维引导辞赋发展。冊庸置疑, 其代表着当时文学批评之中文经之别开始消退, 彼此之间关联愈发多样。

由于魏晋南北朝时期, 儒家经典一直被文学家视为创作灵感的源泉。受 此影响, 儒家经典无论是审美情操、文学理念甚至是表现手法均在文学作品 中有着深度体现。究其根源, 无论儒家经学亦或是文学均有着长足进步; 同 时文学家与经学家往往身为一人。魏晋南北朝其文学造诣与文论成就日趋健 全, 文学成就为人称道, 称之为 “文学自觉时代” 。此时文学家与经学家常 常一人兼之。《三国志・魏书》之中明确写道, “丧乱以来, 十有五年。后生 
者不见仁义礼让之风, 吾甚伤之, 其令郡国各修文学, 县满五百户置校官, 选其乡之俊造而教学之, 庶几先生之道不废, 而有以益于天下” [6]。曹操《修 学令》要求各地设立文学官员。其中当县达到五百户, 即设置校官职位, 选 择青年才俊加以教导, 来倡导仁义礼让的社会风气, 使君王之道不至于废弃。 此即曹魏面对儒家经学日趋下滑的应对举措。身为目光长远的政治巨擘, 曹 操一直认识到 “仁义礼让” 对于维护国家统治可谓意义深刻, 因而面对经学 衰败乱象予以制衡。得益于曹魏 “休养生息”, 待西晋时, 各派经学立入学 官蔚然成风, 经学影响程度日益健全。南北朝由于政治因素, 导致经学呈现 南北对峙局面, 诚然其风格有所区分, 然其发展均有所造诣, 值得肯定。宋 文帝设四馆, 即儒学、玄学、史学和文学四个学馆, 都是分科大学之初始; 宋明帝提五部, 分儒、道、文、史、阴阳都将儒家经学列在榜单头名, 文学 作为独立的学科与经史相分离。

\section{4. 结语}

文章通过文献研究法分析研究发现魏晋南北朝时期文学批评与《诗》学 关系密切, 刘劦思在其《文心雕龙》中针对屈原作品等楚辞代表加以评析时, 同样恪守汉代儒学理念。经学于魏晋南北朝已然趋于衰退, 然其凭借丰沛底 蕴, 依旧是社会思潮中的重要组成。但是释教渐盛, 道学传播, 经学其在左 右冲击之下, 展现出很强的生命力与渗透力。上至帝王, 下至百姓, 均恪守 经学应用于生活实践之中, 将之作为思想行动的指南。再者, 儒家经典亦被 视为文学创作宝库, 不少经学精髓已然转变为文学的具体组成。魏晋南北朝 不少文学高人同样亦是经学大家。儒家经学直接影响着其创新理念的生成, 同样对其文学批评观有着直接影响, 对他们的创作与文的形成影响非常大。 因此, 在文学批评中援经说理, 以经品人成了这一时期文学批评的一个普遍 现象。当然, 本文仍有许多研究的不足之处。如魏晋南北朝时期文学理论、 作品成果数不胜数, 还不能做到更深程度的挖掘分析; 就作品具体风格及个 性还未涉及; 文学创作的标准话问题还未深入探讨。这些都将成为未来具体 研究的方向。

综合观之, 魏晋南北朝时期诗学挣脱儒家经学的束缚, 政治教化已不是 文学创作的唯一标准。文学与玄学、史学、儒学并列, 成为一个独立的门类。 虽然此时的经学没有汉代那么繁荣, 但也多少有所继承, 为这个时期的文学 发展做出了贡献, 在文学领域得到璀璨呈现。此时文学家与经学家不再泾渭 分明, 受益于此, 文学成就呈现井喷之势, 堪称光华灿烂。

\section{基金项目}

此文系阿坝师范学院校级一般项目 “魏晋南北朝文学批评与经学中《诗》 学的关系” (ASB21-18)的研究成果之一。

\section{Conflicts of Interest}

The authors declare no conflicts of interest. 


\section{References}

[1] 阮元, 校刻. 十三经注疏[M]. 北京: 中华书局, 1980: 269.

[2] 班固, 著. 汉书[M]. 北京: 中华书局, 1964: 3170 .

[3] 房玄龄, 著. 晋书[M]. 北京: 中华书局, 1974: 1454.

[4] 扬雄, 著. 李守奎注[M]. 扬子法言, 译注. 哈尔滨: 黑龙江人民出版社, 2003: 16 .

[5] 刘劦思, 著. 文心雕龙注 $[\mathrm{M}]$. 范文澜, 注. 北京: 人民文学出版社, 1958: 475, 39.

[6] 陈寿, 著. 三国志[M]. 裴松之, 注. 武汉: 崇文书局出版社, 2010: 4.

\section{Appendix (Abstract and Keywords in Chinese) 魏晋南北朝文学批评与经学中《诗》学的关系}

摘要: 经学是中国文化价值体系的反映。在魏晋南北朝时期, 经学与文学关 系密切, 可以说二者根本没有绝对的界限。特别是魏晋南北朝时文学批评领 域的文学与此时的经学思想中的《诗》学的关系非常密切。从一些文学品评 的话语中可以看出, 他们多受到《诗》学中诗教观念等的影响。本文寄希望 于针对魏晋南北朝时期文学批评以及《诗》学之间的关联性予以探讨。

关键词: 诗学, 文学批评, 魏晋南北朝, 儒家经学 